Computer Multitasking in the Classroom: Reduced Learning versus Modern Living

Hertzum, Morten; Björneborn, Lennart

Published in:

interactions

DOI:

$10.1145 / 3381022$

Publication date:

2020

Document version

Peer reviewed version

Citation for published version (APA):

Hertzum, M., \& Björneborn, L. (2020). Computer Multitasking in the Classroom: Reduced Learning versus Modern Living. interactions, 27(2), 66-70. https://doi.org/10.1145/3381022 


\title{
Computer Multitasking in the Classroom: Reduced Learning versus Modern Living
}

\author{
Morten Hertzum and Lennart Björneborn \\ University of Copenhagen, Denmark
}

\section{Insights}

- Students tend to agree that multitasking in class is a natural part of modern everyday life

- They also tend to agree that it reduces their understanding of the course material

- The $\mathrm{HCl}$ community has a role in devising ways of reducing the temptation to multitask

\section{Introduction}

Computers have entered the classroom. They have largely replaced pen and paper for note taking, at least in European and North American universities. In addition, many students read course texts on their computer, rather than in hardcopy, and in-class exercises rely on student access to online information or simulations. Yet, these productive uses of computers to facilitate and augment learning are not the only ways in which computers have entered the classroom. By making social media, games, email, and the like readily available they are also a source of distraction. The human-computer interaction $(\mathrm{HCl})$ community can help understand the various consequences of computer use in the classroom and support students and educators in coping with them.

The in-class use of computers and other digital devices for non-study purposes is an instance of multitasking in that the students attend class while at the same time also attending to, for example, social media. Such multitasking has become a concern because it is widespread and because it shifts attention away from the study activities, thereby reducing learning [1, 2]. In-class multitasking has, for example, been found to lower students' academic performance more consistently than time spent studying improves it [2]. In addition, multitasking may not only distract the students who multitask but also those who sit nearby [3]. As a consequence, some universities have policies that regulate the use of computers in class, in some cases including that teachers may request "lids down" and sanction noncompliance with ejecting the student from the classroom [4].

While multiple studies have assessed the learning consequences of multitasking in class [e.g., 1, 3], we take an $\mathrm{HCl}$ approach and ask what students think about such multitasking. Their thoughts are important in understanding computer multitasking in the classroom as well as for the creation of functional remedies. To get data about students' use of computers in class and during their preparations for class we administered a survey to undergraduate students in information science at the University of Copenhagen. Following on from the survey, we discussed with the students their views on computer multitasking in class. For more information about the study method, see the sidebar. 


\section{Sidebar: Method}

We administered a survey to undergraduate students in information science at the University of Copenhagen, Denmark, to get data about their use of computers in class and during their preparations for class. The survey consisted of a paper form that was handed out in class, completed on the spot, and handed in after about five minutes. We administered the survey for three consecutive years (20172019) as part of a mandatory course. Participation in the survey was voluntary and anonymous. All students present in class chose to respond to the survey, but one respondent was removed from analysis because several questions were left unanswered. We received a total of 142 complete responses.

The survey had nine questions. The first four questions (see Table 1) were answered on a 7-point rating scale with the end points "Never" and "Always", the remaining five questions (see Table 2) on a 7point rating scale with the end points "Completely agree" and "Completely disagree". At the top of the survey form, multitasking was defined as "undertaking several activities at the same time" and it was specified that in the context of the survey multitasking specifically referred to "the use of their computer and/or phone for other activities simultaneously with the acquisition of course material."

After the students had handed in the survey, we talked with them about their views on multitasking and the use of computers in class. These discussions were documented in notes written after class.

\section{Widespread computer use}

The respondents use their computers (we use the term computer as a shorthand for computer, tablet, phone, and other digital devices) to facilitate their understanding of the course material, for example by taking notes. In class, the median use of computers for study-relevant purposes is 7 (i.e., "Always"), in preparing for class it is 6 , see Table 1 . The overwhelming use of computers for study-relevant purposes shows that for most of the respondents a strict lids-down policy would clash with their legitimate use of their computer. However, the respondents also use their computer for studyirrelevant multitasking. In class, the median use of computers for such multitasking is 4 (i.e., midway between "Never" and "Always"), in preparing for class it is even more common, see Table 1. Only $4 \%$ of the respondents never multitask in class, whereas $15 \%$ of them always do it while preparing for class.

Table 1. Respondents' computer use in class and during preparations for class, $N=142$ students. The median response category is shown in bold blue.

\begin{tabular}{|c|c|c|c|c|c|c|c|}
\hline \multirow[t]{2}{*}{ Question } & \multicolumn{6}{|l|}{ Never } & \multirow{2}{*}{$\begin{array}{c}\text { Always } \\
7\end{array}$} \\
\hline & 1 & 2 & 3 & 4 & 5 & 6 & \\
\hline $\begin{array}{l}\text { 1. In class I use my computer/phone to facilitate } \\
\text { my understanding of the course material, for } \\
\text { example by taking notes }\end{array}$ & 3 & 1 & 2 & 3 & 10 & 18 & 105 \\
\hline $\begin{array}{l}\text { 2. In preparing for class I use my computer/phone } \\
\text { to facilitate my understanding of the course } \\
\text { material, for example by taking notes }\end{array}$ & 2 & 6 & 9 & 9 & 21 & 33 & 62 \\
\hline $\begin{array}{l}\text { 3. In class I use my computer/phone for email, } \\
\text { social media, games or other multitasking }\end{array}$ & 5 & 25 & 25 & 24 & 27 & 25 & 11 \\
\hline $\begin{array}{l}\text { 4. While preparing for class I use my } \\
\text { computer/phone for email, social media, games, } \\
\text { or other multitasking }\end{array}$ & 8 & 15 & 16 & 21 & 26 & 34 & 22 \\
\hline
\end{tabular}




\section{Computer multitasking reduces learning}

Turning from the respondents' behavior to their assessment of it, we find that they tend to be aware that computer multitasking influences their learning negatively. With a median of 2 the respondents strongly, but not completely, agree that multitasking in class reduces their understanding of the course material, see Table 2 . They weakly agree (i.e., a median of 3 ) that multitasking during their preparations for class reduces their understanding. While the central tendency points toward agreement, $20 \%$ of the respondents disagree - weakly, strongly, or completely - that multitasking in class reduces their understanding. Similarly, $27 \%$ agree that multitasking in preparing for class reduces their understanding.

Multitasking in class may also be a social issue because the students who sit within viewing range of a multitasking student's computer can unwillingly be distracted by its content. With a median of 4 the respondents neither agree nor disagree that they are distracted by other students' multitasking. The responses to this question are fairly evenly spread across the response categories, but we find it noteworthy that $25 \%$ of the respondents completely or strongly agree they are distracted, see Table 2.

Table 2. Respondents' assessment of computer multitasking in class and during preparations for class, $N=142$ students. The median response category is shown in bold blue.

\begin{tabular}{|lccccccc|}
\hline Question & $\begin{array}{c}\text { Completely } \\
\text { agree } \\
1\end{array}$ & 2 & 3 & 4 & 5 & 6 & $\begin{array}{c}\text { Completely } \\
\text { disagree }\end{array}$ \\
\hline $\begin{array}{l}\text { 5. My understanding of the course material is } \\
\text { reduced when I multitask in class }\end{array}$ & 31 & 43 & 22 & 17 & 14 & 9 & 6 \\
\hline $\begin{array}{l}\text { 6. My understanding of the course material is } \\
\text { reduced when I multitask during my preparations } \\
\text { for class }\end{array}$ & 31 & 30 & 25 & 17 & 20 & 11 & 8 \\
\hline $\begin{array}{l}\text { 7. It distracts me when other students multitask } \\
\text { on their computer/phone during class }\end{array}$ & 14 & 22 & 16 & 20 & 15 & 21 & 34 \\
\hline $\begin{array}{l}\text { 8. Multitasking in class is a natural part of modern } \\
\text { everyday life }\end{array}$ & 31 & 30 & 32 & 24 & 10 & 9 & 6 \\
\hline $\begin{array}{l}\text { 9. Multitasking in preparing for class is a natural } \\
\text { part of modern everyday life }\end{array}$ & 42 & 35 & 23 & 18 & 9 & 11 & 4 \\
\hline
\end{tabular}

\section{Part of modern life}

Finally, we asked the respondents whether computer multitasking in class and in preparing for class is a natural part of modern everyday life. They weakly agreed for multitasking in class and strongly agreed for multitasking in preparing for class, see Table 2. The respondents' answers to these two questions correlate significantly with their answers to the questions about how frequently they multitask. The more the respondents multitask in class, the more they consider multitasking in class a natural part of modern everyday life $\left(r_{s}=-.38\right)$. And the more they multitask in preparing for class, the more they consider such multitasking a natural part of modern everyday life $\left(r_{s}=-.38\right)$.

The question about whether it is natural to multitask in preparing for class also correlates significantly with the question about whether the respondents' understanding is reduced by multitasking during preparations for class: The more the respondents consider multitasking in preparing for class a natural 
part of modern everyday life, the less they agree that their understanding of the course material is reduced by multitasking during their preparations for class $\left(r_{s}=-.26\right)$. A similar correlation was not present between the questions about whether it is natural to multitask in class and whether in-class multitasking reduces understanding.

\section{Discussion}

With students tending to accept computer multitasking in class as a natural part of modern everyday life, there is a risk that it becomes a largely unquestioned study practice. The consequences of unquestioned multitasking are easily overlooked, but they are no less real than the consequences of other human-computer interactions. In the oral discussion after the survey, the students confirmed and elaborated the survey responses. Five points stand out from the discussion.

First, while the students as a whole recognize that computer multitasking reduces their understanding of the course material, they appear to perceive multitasking as a condition dictated by modern everyday life. Several students mention an expectation from their surroundings to receive almost instant responses to mails, texts, and status updates. This expectation makes them feel obliged to attend to social media in class. The students find that if they do not respond immediately they often forget to respond at all and, thereby, definitely do not meet the expectations from their surroundings. Furthermore, many of the students get popups or other notifications whenever they receive new content. Once the notification has interrupted them, they feel that they might just as well respond straightaway. Thus, multitasking in class involves a tension between social consideration toward classmates (not wanting to distract them) and social consideration toward friends online (not wanting to let them wait).

Second, the students mention that they have been around computers all their lives - in class as well as everywhere else. When they went to elementary school they brought their computers with them; in high school they also brought their computers; and now they do the same at university. They have no experience of a life without computers. One student feels that, by extension, they also have no way of assessing whether multitasking reduces their learning: "We have never tried anything other than having FB [Facebook] right at our fingertips." Another student counters this comment by noting that at the beginning of in-class group work it is very apparent when someone has been distracted by multitasking and not heard what they are to do in the groups. This example also shows how multitasking may affect the students who themselves refrain from multitasking.

Third, consistent with the survey question about other students' multitasking the students orally express different opinions about whether they are negatively affected by other students' multitasking. Several students are unaware that their multitasking affects some of their classmates. One student expresses the opinion that they have become blind to other people's screens: "We are used to being around people who have their computer or phone open, so we have learned not to be distracted by what happens on their screen." This opinion resembles the notion of banner blindness, which is supported by studies finding that people rarely look directly at banners and have difficulty remembering them [5]. However, the same studies find that banners are disliked and may slow users down, thereby seemingly contradicting the assertion that users are blind to banners.

Fourth, the students also talk about another, more pro-active use of multitasking. They struggle to focus nonstop on the study activities in class; to focus on the study activities most of the time they allow themselves occasional pauses. Checking social media for status updates is a means of creating such a pause. According to several of the students these pauses are necessary and improve their overall in-class learning. If they did not create these pauses by multitasking on their computer then they would probably do it in other ways, such as by daydreaming or doodling. They perceive social media a good means of creating a small pause because social media can be attended whenever the individual student needs a pause, rather than when there is a break for the entire class. However, once 
their attention is diverted away from the study activities there is a risk that the students remain on social media for more than a small pause [2]. Social media tend to be attention-grabbing.

Fifth, some of the students are interested in knowing how it is to teach if a sizeable fraction of the students are multitasking rather than attending to the activities in class. This interest reflects a recognition that multitasking may not just influence the students' learning but also the teacher's experience and possibly the quality of the teaching.

\section{What to do about it?}

It is not easy to fix something that the students perceive more like an inevitable condition than recognize as a solvable problem. The $\mathrm{HCl}$ community has a role in reminding students, teachers, and others that computer multitasking in class has too severe consequences to be treated as inevitable. It should also be investigated whether multitasking in class is perceived or performed differently by students with other cultural backgrounds, including students outside of Europe and North America. While the students in the present study express the overall opinion that not much can be done to reduce their multitasking, three key issues were brought up in the discussion:

First, the majority of the students see it as the individual students' personal responsibility whether they multitask to an extent that reduces their learning. As a consequence, their primary proposal for how to lessen multitasking is for the individual student to exercise self-discipline. Their strategies include the use of apps for limiting time online and choosing to sit in the front row to avoid distraction from other screens. Recognizing computer multitasking in class as a systemic, rather than individual, responsibility will reframe the problem and point toward different remedies.

Second, many of the students are opposed to classroom-wide restrictions imposed by the university or teacher. For example, they consider it unrealistic and too drastic to demand "lids down" or block access to social media. While such classroom-wide interventions have been put forward in the literature [e.g., 4, 6], they find little support among the students in this study. The inadequacies of previously tried systemic remedies should fuel the design of new remedies. Maybe, social-media blocking will be perceived differently if it is turned on and off in class by the teacher in dialogue with the students.

Third, some students express that one-way, lecture-style teaching makes them feel that it is more acceptable to visit social media. This suggests that the teaching style may be a way for teachers to reduce multitasking in their classroom. Brief pairwise reflections, in-class group work, and other elements of dialogue-based teaching reduce the temptation to multitask by engaging the students more in the classroom activities. Thus, another way for the $\mathrm{HCl}$ community to help combat computer multitasking in class could be to devise support for dialogue-based teaching, thereby fostering the attitude that learning is a shared responsibility among students and teacher. This may counteract social contagion patterns through which students multitask because they witness other students' multitasking and experience "a sense of permission that opting out is OK" [6].

\section{References}

[1] Zhang, W. Learning variables, in-class laptop multitasking and academic performance: A path analysis. Computers \& Education, 81 (2015), 82-88.

[2] Bellur, S., Nowak, K. L. and Hull, K. S. Make it our time: In class multitaskers have lower academic performance. Computers in Human Behavior, 53 (2015), 63-70.

[3] Sana, F., Weston, T. and Cepeda, N. J. Laptop multitasking hinders classroom learning for both users and nearby peers. Computers \& Education, 62 (2013), 24-31.

[4] Cismaru, R. and Cismaru, M. Laptop use during class: A review of Canadian universities. Journal of College Teaching \& Learning, 8, 11 (2011), 21-28. 
[5] Burke, M., Hornof, A., Nilsen, E. and Gorman, N. High-cost banner blindness: Ads increase perceived workload, hinder visual search, and are forgotten. ACM Transactions on Computer-Human Interaction, 12, 4 (2005), 423-445.

[6] Shirky, C. Why I just asked my students to put their laptops away. https://medium.com/@cshirky/why-i-just-asked-my-students-to-put-theirlaptops-away-

7f5f7c50f368 (accessed March 31, 2019). 